\title{
Penfigoide ampolloso asociado al uso de rivaroxaban
}

\author{
Bullous pemphigoid associated with rivaroxaban use \\ Ali Carolina Martínez Murillo, ${ }^{*}$ Gabriela Castrejón Pérez, ${ }^{*}$ \\ Daniel Hernández Salcedo, ${ }^{\ddagger}$ Raúl Valencia López ${ }^{\S}$
}

Citar como: Martínez MAC, Castrejón PG, Hernández SD, Valencia LR. Penfigoide ampolloso asociado al uso de rivaroxaban. Acta Med. 2020; 18 (4): 422-423. https://dx.doi.org/10.35366/97272

Femenino de 74 años que ingresa a hospitalización de medicina por diabetes mellitus tipo 2 descontrolada por hipoglucemia. A la exploración: dermatosis localizada en tronco anterior, posterior y tercio proximal de brazos caracterizada por múltiples lesiones ampollosas de contenido seroso, algunas denudadas, costras hemáticas y máculas eritematosas, pruriginosas; refiere que dicha condición comenzó en enero posterior a consumo de rivaroxabán.

El penfigoide ampolloso es una enfermedad inflamatoria, crónica, autoinmunitaria en la que existen anticuerpos dirigidos contra antígeno del penfigoide ampollar. ${ }^{1}$

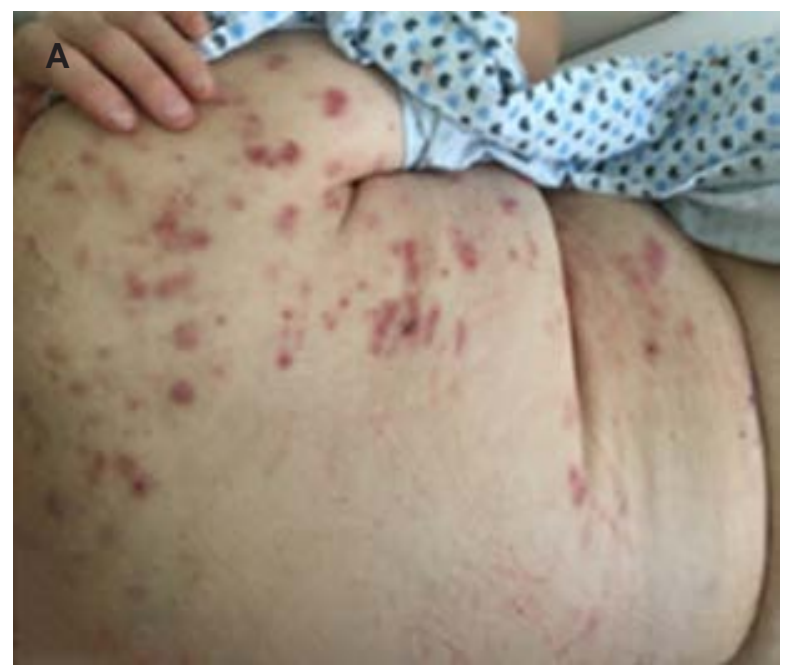

Se presenta con predominio en la tercera edad, afecta extremidades tronco y abdomen; lesiones en mucosa sólo se observan entre 10 y $30 \%$ de los casos, se caracteriza por ser diseminada, bilateral con ampollas tensas de contenido claro, dejando áreas erosionadas y costrosas. ${ }^{1}$

Aunque las erupciones de penfigoides inducidas por fármacos son poco frecuentes, pueden ser causadas por ciertos fármacos como la furosemida, heparinas, ibuprofeno, neurolépticos y captopril, entre otros. ${ }^{2}$

En la literatura se han notificado reacciones cutáneas asociadas a anticoagulantes cumarinicos, heparinas no

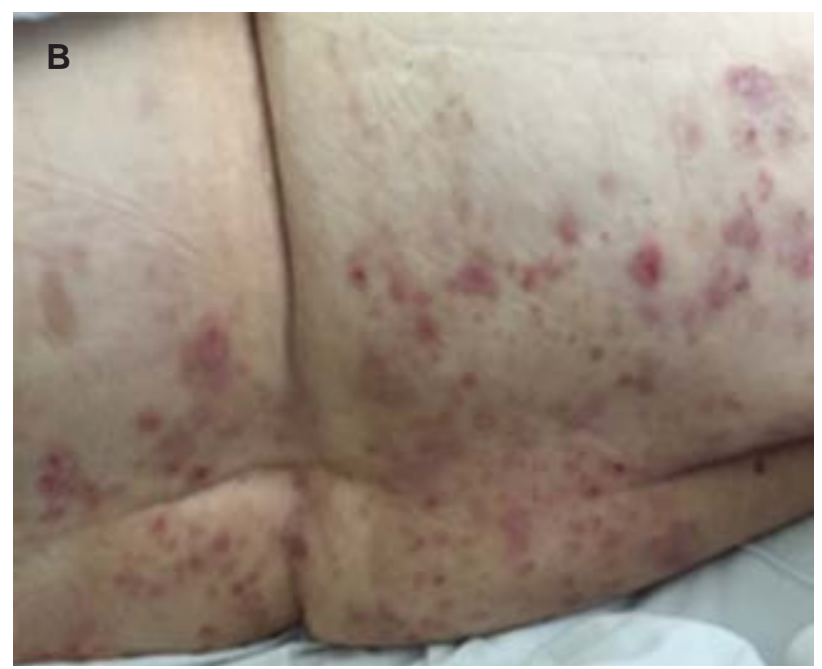

Figura 1: Clínica.

* Médico residente de primer año de medicina interna.

‡ Profesor titular del curso de medicina interna.

$\S$ Profesor adjunto del curso de medicina interna.

Hospital Ángeles Clínica Londres.
Correspondencia:

Ali Carolina Martínez Murillo

Correo electrónico: alimtzmurillo@hotmail.com

Aceptado: 06-02-2020.

www.medigraphic.com/actamedica

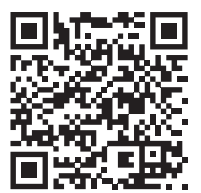




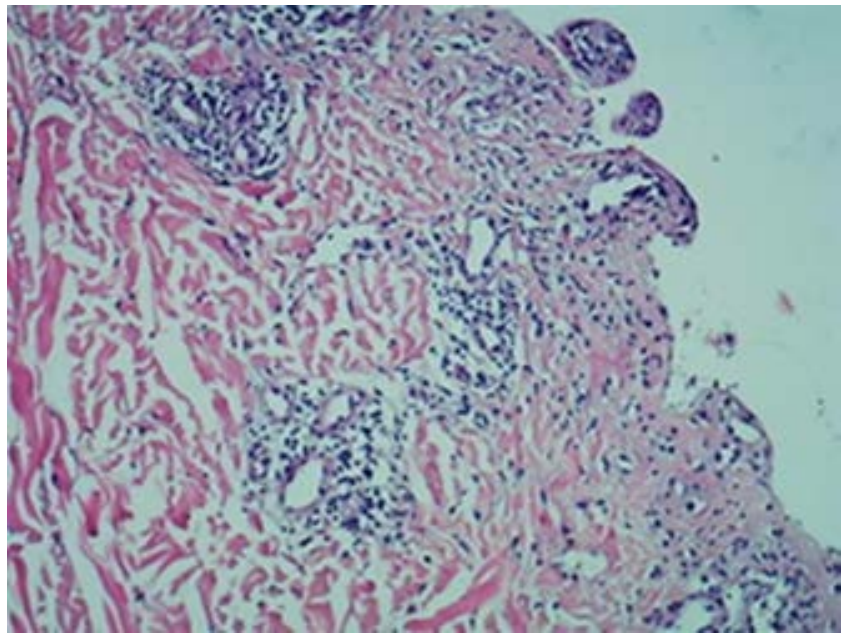

Figura 2: Histológica.

fraccionadas y de bajo peso molecular y los nuevos anticoagulantes inhibidores del factor Xa. ${ }^{1,3}$

Las lesiones cutáneas van desde reacciones pruriginosas leves, pérdida de pelo, eritema y/o edema en sitio de aplicación hasta dermatosis ampollosas hemorrágicas como las presentadas por Ferreira C y colaboradores ${ }^{2,4}$

En la literatura se han reportado pocos casos de penfigoide ampolloso por anticoagulantes, dos de ellos fueron secundarios a enoxaparina descritos por Dyson SW y su equipo ${ }^{5}$ y uno más al uso de rivaroxabán notificado como el primer caso de esta índole, dichas lesiones aparecieron entre tres días y dos semanas del inicio de los fármacos. ${ }^{2}$

\section{CONCLUSIÓN}

Nuestro caso es similar al reportado por Shim J y colaboradores, ya que las lesiones se presentaron posterior al inicio del medicamento y remitieron al retirarlo. Es importante prestar atención a los informes de pacientes con posibles efectos adversos después de iniciado el tratamiento.

\section{REFERENCIAS}

1. Shim J, Chung S, Kim B, Kim S, Lee K, Yoon Y, Chang Y. Bullous hemorrhagic dermatosis due to enoxaparin use in a bullous pemphigoid patient. Asia Pac Allergy. 2017; 7: 97-101.

2. Ferreira C, Oliveira A, Furtado A, Rocha A, Ribeiro J. Bullous pemphigoid-like skin eruption during treatment with rivaroxaban: a clinical case study. Eur J Case Rep Intern Med. 2018; 5 (3): 000724.

3. Eek A, Oddvar B, Bakkehoi G, Stenberg-Nilsen H. Anticoagulantassociated adverse drug reactions in 2013-15. Tidsskr Nor Laegeforen. 2018; 138 (12).

4. $\mathrm{Vu}$ TT, Gooderham M. Adverse drug reactions and cutaneous manifestations associated with anticoagulation. J Cutan Med Surg. 2017; 21 (6): 540-550.

5. Dyson SW, Lin C, Jaworsky C. Enoxaparin sodium-induced bullous pemphigoid-like eruption: a report of 2 cases. J Am Acad Dermatol. 2004; 51 (1): 141-412.

Conflicto de intereses y financiamiento: Ali Carolina Martínez, Gabriela Castrejón, Daniel Hernández y Raúl Valencia declaran que no tienen ningún conflicto de intereses. Financiamiento, ninguno. 